\title{
Cruzar o mar na formação e na ação: narrativas de professores portugueses e brasileiros
}

\author{
Silvia Maria Medeiros Caporale* \\ Teresa Jacinto Sarmento
}

\begin{abstract}
Resumo
A mobilidade de pessoas entre países é muito comum nos dias de hoje, e, ao se movimentarem as pessoas levam consigo saberes, experiências e propósitos. Assim acontece com alguns professores que fazem a sua formação no Brasil e mais tarde exercem a docência em Portugal; assim acontece também com professores que se formam em Portugal e desenvolvem a sua ação docente no Brasil. É neste caminho de ida e volta que, no contato direto com professoras que fizeram essas viagens, procuramos analisar como as mesmas mobilizam para as suas narrativas os seus saberes e experiências para se desenvolverem como profissionais e dar as melhores respostas aos seus alunos, em países que as acolhem após esse período formativo. As conclusões apontam para um amplo conjunto de indicadores da identidade de ser professor, como a interação ser a base de toda a ação educativa, a riqueza que o cruzamento de saberes e experiências proporciona e a pertinência da contextualização educativa.

Palavras-chave: narrativas, formação docente, transculturalidade
\end{abstract}

\section{Crossing the sea in teaching education and action: Portuguese and Brazilian teachers' narratives}

\begin{abstract}
The movement of people between countries is quite common nowadays and when moving around people carry with them knowledge, experiences and purposes. This is what happens to teachers who are trained in Brazil and later start teaching in Portugal; that's also what happens to teachers who graduate in Portugal and develop their teaching career in Brazil. It is in these comings and goings, through the direct contact with teachers who have undertakensuch journeys, that we tried to analyze how they mobilize, for their narratives, knowledge and experiences for them to grow as professionals and to give the best answers to their students, in countries that welcome them after their teacher education period. Conclusions indicate a wide set of indicators for the teachers' identity, such as, the interaction as the basis for all the educational action; the richness promoted by the exchange of knowledge and experiences and the relevance of the educational contextualization.
\end{abstract}

Key words: narratives, teacher education, transculturality

\section{Introdução}

A mobilidade de pessoas entre países é muito comum nos dias de hoje, prevendo-se que, ao se movimentarem, as pessoas levem consigo saberes, experiências e propósitos. Assim acontece com alguns professores que fazem a sua formação no Brasil e mais tarde exercem a docência em Portugal; assim acontece também com professores que realizam formação em Portugal e desenvolvem a sua ação docente no Brasil.

Ser professor integra componentes comuns, elementos transversais que transcendem em muito o local primário da formação, ainda que essas estruturas de base sejam fundamentais para a construção de identidades profissionais bem referenciadas. Ser professor exige também uma contextualização adequada de forma a ser possível encontrar o percurso certo para ajudar a transformar as experiências em aprendizagens.

No presente trabalho, no contato direto com

\footnotetext{
* Endereço Eletrônico: silviammcaporale@hotmail.com
}

** Endereço Eletrônico: tsarmento@ie.uminho.pt professoras que fizeram estas viagens, procuramos analisar como elas, nos seus trajetos de ida e volta, mobilizam para as suas narrativas os seus saberes e experiências para se desenvolver como profissionais e dar as melhores respostas aos seus alunos. Como se situam na ação docente? Como fazem a sua inserção socioideológica e política? O que ganham e o que perdem nestas transações? Que significados se atribuem enquanto professoras? A resposta a estas questões passa por uma reflexão prévia em torno de conceitos como identidades profissionais, saberes docentes, experiência e formação.

A escolha de narrativas como recurso metodológico tem como base a valorização das histórias de vida do professor, a relevância da sua voz, entendendo que dessa forma é possível compreender a complexidade

de enredos entre tempos e espaços configuradores das identidades singulares, construídas nas múltiplas interacç̧ões 
entre o passado, o presente e o futuro, o herdado e o projectado, as continuidades $e$ as rupturas, as ligações e os confrontos do sujeito consigo próprio e com os actores que povoam os contextos em que se move (SARMENTO, T.,2002, p. 258).

Nesta investigação, com base no reconhecimento dos sujeitos como co-construtores de conhecimento, damos voz a duas professoras, à Teresa e à Analúcia, sendo que a primeira realizou a sua formação pedagógica inicial e desenvolveu alguma atividade profissional no Brasil e atualmente atua no sistema educativo português (anos iniciais do ensino fundamental), e a segunda, professora brasileira, com formação de base feita no seu país, tendo posteriormente prolongado a sua formação em Portugal, atualmente leciona no Brasil (educação infantil). Da análise das suas narrativas procuramos explicitar alguns indicadores da identidade de ser professor, como, por exemplo, a interação ser a base de toda a ação educativa, a riqueza que o cruzamento de saberes e experiências proporciona, a necessidade de cada um conseguir fazer o cruzamento entre vivências pessoais e profissionais e a pertinência da contextualização sócio-histórica e política da ação educativa.

Assim, o texto será construído na interação direta do saber científico já constituído e as narrativas das professoras. Não se pretende com isto que as falas sejam ilustrativas da teoria, mas sim que a ajudem a expandir, a introduzir no leitor novos questionamentos, potenciando a leitura como novo processo reflexivo e, como tal, formativo.

\section{Cruzar o mar}

Eu quando cheguei ao Brasil nunca me adaptei (...) porque como nós morávamos em Angola e tinha muito campo para brincar (...) na Avenida Cupecê (em S.Paulo) não tinha lugares para brincar $e$ achava aquele lugar muito barulhento (...) para mim Angola era Portugal e eu dizia sempre: "Eu quando crescer vou-me embora, eu quando crescer vou-me embora." E depois com o trabalhar em Diadema, eu quis trabalhar nas favelas, estive muito ligada às favelas, e então estive no Eldorado, estive em Santo Amaro, estive no Serraria, e estive muito centrada ali mesmo com a parte mais carenciada. (TERESA, 2014)
Teresa relata a experiência de ter passado por diferentes países de língua oficial portuguesa, em períodos históricos ainda recentes, em que Angola, por exemplo, era ainda uma colônia portuguesa. Cruzar o mar foi uma experiência precoce na vida dessa professora, o que, como veremos, irá influenciar a sua forma de ver e estar na educação.

Concretamente, entre Portugal e o Brasil a movimentação de povos, diz a história que se teria iniciado em 22 de abril de 1500, quando da chegada da frota comandada por Pedro Álvares Cabral a esse território, dando assim início a um longo, múltiplo de sentidos e forte estreitamento de relações entre portugueses e brasileiros. Estes dois povos cresceram irmanados, com base numa língua comum, mas com culturas em muitos âmbitos diversas. Essa também foi a percepção de Analúcia, ao narrar:

A experiência em Portugal, Braga foi única. Estive por um ano, eu e meu marido, realizando um grande desejo, estudar $e$ conhecer uma cultura tão próxima e, ao mesmo tempo, tão diferente da nossa. (ANALÚCIA, 2014)

Nas duas últimas décadas têm-se estreitado os laços entre professores de um e de outro lado do Atlântico, interessados, uns e outros, em refletir, conhecer e aprender conjuntamente realidades educativas que, ainda que diversas, comportam a finalidade comum que é a Educação. Assim sendo, encontramos em Portugal professores (brasileiros e portugueses) que realizaram formação no Brasil, como é o caso de Teresa:

fui para Filinto Muller, em Diadema, porque lá tinha o Magistério, habilitava para o $1 .^{\circ}$ Ciclo. Depois fiz 4 anos para ter a Educação de Infância. E então saía com 1. ${ }^{\circ}$ Ciclo e Educadora de Infância, 4 anos. Então eu comecei na verdade com 16 anos. Fiz Pedagogia os 3 anos completos e depois fiz Administração Escolar mas cursei os 4 anos completos. (...) Até porque depois fiz muitas formações. Porque nós lá em Diadema fizemos muitas formações. Eu estive lá na época do investimento, que foi quando entrou o Pete, que investiu muito na educação em Diadema e eu estava exatamente nessa época. (TERESA, 2014) 
Encontramos no Brasil professores (portugueses e brasileiros) que realizaram formação em Portugal, como afirma Analúcia: "Em 2008 fiz meu pós-doutorado na UMinho, em Braga, Portugal".

Ao se movimentarem as pessoas levam consigo saberes, experiências e propósitos, num processo transcultural que nos interessa compreender. Peixoto (2009, p. 49) define transculturalismo como o "entrelaçamento das culturas para a produção do conhecimento e da própria realidade social e individual". A mobilização do conceito de heterotopia de Michel Foucault ajuda-nos a clarificar esta definição. Foucault (2002) desconstrói este conceito indo ao étimo grego das palavras que o compõem: hetero = outro; topia (de tópos) = outro lugar. Nesse sentido, existe sempre um campo transcultural, no qual a comunicação e a informação "ganham corpo pela participação ativa dos seus componentes - artes, filosofia, religiões, ciências, conhecimentos jurídicos e saberes das pessoas" (PEIXOTO, 2009, p. 49). Assim, na nossa análise, um professor que se desloca de um país para outro é embebido por este 'campo transcultural', fazendo a mediação - é participante - entre o que traz e o que encontra, pondo em articulação os seus referenciais culturais prévios com os presentes no momento da ação. Dessa forma também parece ter acontecido com Analúcia:

A UMinho é uma referência como Universidade, seu corpo docente é qualificado, comprometido e o ambiente é extremamente respeitoso. Quando iniciei minhas aulas nas disciplinas que TS me indicou como forma de aprofundamento teórico-prático, foi um grande prazer entrar em contato com diferentes culturas, há um grande número de alunos estrangeiros nesta instituição, com professores portugueses, com tudo o que é oferecido pela instituição, oficinas, palestras, workshops, congressos, eventos em geral. Realmente uma riqueza intelectual e cultural muito grande.(ANALÚCIA, 2014)

A identidade cultural de um professor nesta situação pode estar em tensão, sobretudo se pretender se fixar rigidamente na sua cultura formativa de origem e não conseguir estabelecer aquela mediação. Cruzar o mar implica que estes professores "movimentem a diversidade social e cultural para que esta se entrelace e contagie, complexamente, com as múltiplas formas de vida e de estar no mundo" (PEIXOTO, 2009, p. 52). Como nos diz Teresa, as experiências em realidades tão diferentes, levam-nos a relativizar cada situação:

"Essa construção de material, esse transformar o nada em tudo, como eu digo, o lixo em material, fez com que eu não ficasse presa às cartilhas do Brasil... e até por Paulo Freire que a gente não deveria estar a usar cartilhas porque elas têm que ser adaptadas à criança, e aqui saber adaptar os manuais.(...) Quando vim para Portugal achava que tinha muito... Hum, enquanto que as minhas colegas diziam "Nós não temos nada para fazer" e eu dizia: "Meu Deus, vou ficar calada, porque eu acho que eu tenho tanto!" e isso me aconteceu e até hoje acontece porque elas reclamam, reclamam, reclamam e eu acho que eu tenho muito. (...) Ainda dizem que não têm nada, eu fico calada porque eu tenho muito, tenho fotocópias conforme eu quiser, mando direto do meu computador para a fotocopiadora, tenho plasticina, tenho barro, tenho... pronto, lá eu fazia o barro com a terra, para moldar as letras para eles trabalharem mas nós íamos buscar água e a terra que estava lá fora e o barro era eu que o fazia. "(TERESA, 2014)

Voltando a Foucault (1984, p. 46), este nos diz que o tempo atual é uma época do espaço, "Estamos na época da simultaneidade, estamos na época da justaposição, a época do perto e do longe, do lado-a-lado, do dispersivo", em que, mais do que a acumulação de conhecimentos que se vai realizando ao longo do tempo, valem as experiências "da rede que conecta pontos e que entrecruza seu novelo" (ibidem). Ou seja, na ação docente, em qualquer momento, para além dos conhecimentos prévios do professor, é especialmente relevante como cada um, com o que sabe e com o que é, consegue promover a construção de conhecimento, no contexto concreto em que se encontra. A importância da contextualização, do reconhecimento de cada identidade local, das crianças com os seus saberes, da sua pertença a uma comunidade específica, justifica-se, ainda com Foucault (1984, p.48), nas razões de que: 
Nós não vivemos em uma espécie de vazio dentro do qual poderíamos colocar indivíduos e coisas. Nós não vivemos dentro de um vazio que poderia ser colorido com diferentes gradações de luz; vivemos dentro de um conjunto de relações que definem sítios, que são irredutíveis uns aos outros $e$ certamente não superponíveis uns aos outros.

Ao lecionar num local diferente daquele em que realizou formação, o professor intervém ativamente num lugar com múltiplas camadas de significação ou de relações a outros lugares, o que leva a um constante processo de ressignificação dos seus saberes. Ouçamos Analúcia:

Tive a oportunidade de estar presente em duas escolas: São Mamede e São Lázaro, exemplos a serem seguidos de um trabalho com qualidade e respeito ao professor e às crianças. Nestas escolas pude inteirar-me mais da vida cotidiana dos portugueses, estar mais próxima das professoras, algo que me cunhou uma marca profunda em meu ser, como professora e pessoa. (vou abrir um parêntese, tenho que fazer uma pausa, pois enquanto escrevo lágrimas me vêm aos olhos, pois tenho um imenso apreço pelas lembranças queridas das pessoas que ai deixei: ... todas as mulheres e as crianças com as quais convivi durante este ano impactaram minhas ações no presente e no futuro. Hoje, sou uma outra pessoa, graças ao período que pude compartilhar com todo este grupo.). (TERESA, 2014)

O fato de cruzar o mar permitiu-lhe o acesso a outros espaços, especialmente significativos porque não são ocos; eles estão impregnados dos significados que esta professora construiu na interação com crianças e adultos em espaços escolares, singularmente marcados pela cultura que os impregna. Nesse sentido, Teresa também levou consigo para Portugal o fruto das diversas experiências profissionais do início de sua carreira no Brasil, trabalhou com crianças da educação infantil e dos anos iniciais (ensino fundamental) e também com os adultos, na educação de jovens e adultos (EJA). Sobre essa última experiência, ela relatou:
Trabalhei no Ceja, trabalhei no Ceja à noite, que eu queria ter essa experiência. Trabalhei com uma senhora, uma outra senhora que eu alfabetizei que tinha 70 e poucos anos mas ela disse que só queria morrer depois de saber ler. E então ensineia com as receitas dos bolos... eu pedia para que ela lesse, ensinava a receita e ela trazia sempre aquela receita que ela conseguia ler e trazia o bolo no dia seguinte. Eu até lhe disse: "olhe, isso assim não pode ser!", eu na época era muito magrinha por isso não me fez muita diferença, tinha na época 44 Kg e então não me fazia muita diferença em comer. Ela me explicava como é que se fazia o bolo, então eu ensinei-a a ler assim. Um dia que ela conseguiu escrever o nome dela, lembro-me perfeitamente de ela dizer, "agora já posso morrer, já sei ler", é realmente uma das coisas mais bonitas de se ver, é gratificante. (TERESA, 2014)

Nesta ordem de ideias, somos levadas a questionar: serão os saberes dos professores universais e contextualizáveis? Qual a transversalidade da profissão professor?

A resposta a estas questões obriga-nos à mobilização do que entendemos sobre formação e saberes dos professores, a(s) sua(s) identidades e o valor da experiência na construção desses saberes e identidade(s).

\section{Formação e saberes profissionais}

A formação e, sobretudo, o que cada profissional faz com a formação que vai realizando, é um fator estruturante nas questões da transculturalidade: conseguir sair do seu espaço de conforto que é o meio em que realizou formação, apoiado por pares formandos e por formadores, para atuar referenciado por essa formação, mas noutro espaço, sem essa base de apoio, implica que cada professor saiba tecer uma rede entre esses saberes prévios e a realidade do novo contexto. Mesmo enfrentando algumas dificuldades emocionais, Analúcia parece ter conseguido realizar essa tecitura na sua volta ao Brasil:

Quando voltei, fiquei um ano, 2009, chorando, não podia falar, lembrar (como agora) dos momentos vividos em Portugal, $e$ ao mesmo tempo tinha que continuar a viver; voltei com a responsabilidade de me 
tornar Coordenadora do Grupo da Educação Infantil da ESEBA. Várias histórias foram sendo contadas por mim em eventos, palestras referente ao que havia estudado e produzido no meu pós-doc; afinal havia uma agenda institucional obrigatória quando se pertence a uma instituição pública federal, há certos compromissos. Mas deixando isto de lado, a parte prazerosa foi poder constituir um grupo na ESEBA de estudos sobre a infância, retomar antigos estudos, realizar outras possibilidades de estar com as crianças, pois em Portugal, isto é visivel, pelo menos nas escolas em que estive. (ANALUCIA, 2014)

Diferentes abordagens podem ser feitas ao conceito de formação: como uma função social de transmissão de saberes ou como um processo de desenvolvimento e de estruturação da pessoa, levada a cabo pelo duplo efeito de maturação interna e de possibilidades de aprendizagem através das experiências dos sujeitos. Nos últimos anos, como lembra Roldão, assistiu-se a um maior investimento na qualidade científica da formação e na dimensão profissionalizante, "corporizada em competências profissionais como eixo estruturador da formação" (2001, p. 6). Roldão reforça esta perspectiva ao chamar a atenção para a relevância de os saberes profissionais se consubstanciarem em saberes científicos sólidos nos seus diferentes planos: do objeto de aprendizagem, dos sujeitos e da relação entre ambos com os seus contextos. Segundo Alonso (1998), a formação de professores integra uma componente pessoal, que se conecta com um discurso axiológico referente a finalidades, objetivos e valores tanto ou mais que às componentes técnicas e instrumentais. Assim, esta formação implica a construção de diferentes tipos de saberes: o saber, o saber-ser e o saber-fazer, sustentados quer nas perspectivas socioeducativas, organizacionais, psicopedagógicas e curriculares, quer nas perspectivas de desenvolvimento humano e de relação social.

$\mathrm{Na}$ linha de Alarcão (2001, p. 21) "pretende-se que os professores de hoje não sejam meros executores de currículos previamente definidos, mas um decisor, um gestor em situação real e um intérprete crítico de orientações globais", o que implica atitudes de pesquisa, de análise critica e substantiva, que faça do contexto educativo, como diria Stenhouse (1995), "um laboratório, e cada professor um membro da comunidade científica" (cit. in Alarcão, 2001, p. 23). Pretende-se ainda afirmar a formação de professores na sua dimensão histórica, ou seja, na sua contextualização espáciotemporal, em que cada profissional atua racionalmente, ou, como tão bem diz Paulo Freire:

Os homens, ao terem consciência da sua actividade e do mundo em que estão, ao actuarem em função de finalidades que propõem e se propõem, ao terem o ponto de decisão de sua busca em si e em suas relações com o mundo, e com os outros, ao impregnarem o mundo da sua presença criadora através da transformação que realizam nele, na medida em que dele podem separar-se e, separando-se, podem com ele ficar, os homens, ao contrário do animal, não somente vivem, mas existem, $e$ sua existência é histórica (1987, p. 105).

Isto é, interessa-nos uma abordagem da formação de professores que atente para a realidade sócio histórica, as crianças situadas em contextos específicos, as pessoas concretas que exercem esta ação profissional e que sobre a mesma realizam uma reflexão crítica. Ora, como nos diz Willms e Carvalho,

Para se realizar esse acto de desvelamento da realidade com vistas à acção, à transformação, é preciso mudar a dinâmica do trabalho educativo, uma vez que ele começa pela pesquisa da realidade em busca do conteúdo, ou seja, a maneira como as pessoas pensam a sua realidade (2008, p. 29).

Como tal, a perspectiva de formação que aqui se aborda é entendida como um processo dinâmico, partilhado entre os atores sociais que a constroem, promovendo o desenvolvimento profissional integrado no âmbito do desenvolvimento pessoal; ou seja, uma formação orientada para a autonomização, a partir da reflexão dos saberes construídos nas práticas, com participação ativa dos atores sociais implicados, considerando a importância da reflexão em ação e a construção de saberes integrados.

Roldão (2001) aponta os princípios norteadores das estratégias de formação conducentes à autonomização, propondo que os futuros professores se apetrechem com saberes de 
referência sólidos no plano científico-profissional, estruturantes e mapeadores do campo do conhecimento profissional; com competências para ensinar, emergentes e integradoras do saber profissional, contextualizadas na ação profissional; com competências de produção articulada com conhecimento profissional gerado na ação e na reflexão sobre a ação, teorizado, questionante e questionável, comunicável e apropriável pela comunidade de profissionais. Canário (2001), dentro da mesma linha de pensamento, chama a atenção para o valor epistemológico da experiência na formação de professores, defendendo que "o mais importante na formação inicial consiste em aprender a aprender com a experiência" (p. 32), o que implica uma relação estratégica entre a formação e o trabalho (iniciada na relação entre as diferentes unidades curriculares teóricas e as práticas pedagógicas, ainda na formação inicial), de forma a possibilitar o saber mobilizar os conhecimentos para as situações específicas que vão ocorrendo.

A noção do saber dos professores, dos seus processos de construção e da sua validade, tem sido amplamente questionada pelas ciências da educação e pelos próprios docentes. Os cursos de formação de professores estão geralmente organizados por duas áreas centrais de saberes: os saberes das ciências da especialidade e os saberes das ciências da educação. A articulação entre estas duas áreas tem sido questionada em diferentes instituições de formação, aumentando os dilemas quando as instituições habituadas a formar professores para áreas disciplinares passam a formar professores de crianças (FORMOSINHO, 2002). Ou seja, os professores do ensino pós-primário, em Portugal, lecionam uma disciplina específica a um número elevado de alunos, organizados por turmas, podendo cada turma ter um grupo diferenciado de professores e fazendo cada professor parte de conjuntos docentes diferentes. Por sua vez, as educadoras de infância - o mesmo acontecendo com os professores do ensino primário - trabalham, em princípio, pelo menos um ano completo com um grupo restrito de crianças, cabendo-lhes promover, para além da componente instrutiva, as componentes socializadora e personalizadora. Além disso, o bom exercício de trabalho com crianças exige um bom trabalho com os pares profissionais, os pais e outros elementos das comunidades.

Os conhecimentos básicos dos professores são assim entendidos como aqueles de que os docentes necessitam para desenvolver um bom ensino, sendo estes compostos por três tipos de saberes: o saber pedagógico, constituído pelos conhecimentos teóricos e conceituais, integrando-se aqui o saber da especialidade; o saber fazer, baseado nos esquemas práticos do ensino; e o saber porquê, sustentado na justificação da prática (MARCELO, 1994; OLIVEIRA-FORMOSINHO, 1998).

A aquisição dos conhecimentos profissionais básicos poderá resultar de diferentes modalidades de aprendizagem, tais como: o contato com resultados da investigação; a análise das experiências de trabalho; trabalhos realizados pelos alunos-profissionais; a observação de professores especialistas; reflexões sobre a prática; conversas com professores. A construção dos conhecimentos profissionais básicos corresponde assim a um processo de aprendizagem complexo, mais complexo ainda quando eles se promovem num e noutro lado do Atlântico, pelo que, mais uma vez, a forma como o professor deles se apropria, é progressivo e individualizado, como podemos perceber da narrativa da Teresa:

Eu acho que o Brasil... Aqui, eu já tinha estudado Pedagogia quando vim para cá, muitas coisas daqui eu já tinha estudado para trabalhar cá, por exemplo conhecer um pouco da história da educação em Portugal. ... no Brasil eu acho que nós damos uma abertura maior de falar com o professor, menos medo talvez, não sei se foi o que eu senti, um à vontade talvez para debater os assuntos. Aqui (em Portugal) sentia falta disso, que nós (no Brasil) da mesma forma que estávamos numa sala de aula, estávamos num jardim sentados todos a conversar e a comer e a tomar uma cerveja e aqui nós não temos uma aproximação tão grande com os professores. Mas a nível académicos vamos dizer que os conteúdos se encontram, porque quando eu fiz o mestrado, as obras que eu tinha lido no Brasil praticamente muitas delas foi o que tive que ler aqui. Muitas também não, que muitas tive que estudar aqui, também já tinha passado muito tempo não é? (TERESA, 2014)

No processo de aquisição e construção de saberes dos professores, o conhecimento que cada um vai elaborando sobre o grupo em quem recai a sua ação é mediado pela ideia de criança, conhecimento esse que tenderá a ter uma 
sustentação pluridisciplinar. A individualização da ação educativa, a capacidade de atender a cada aluno com a sua história única, os seus conhecimentos, as suas dificuldades e as suas reações, será assim uma das bases de construção do saber profissional docente.

A acepção de saber prático quotidianamente construído dirige-se à reflexividade produzida sobre a experiência diária, podendo assim traduzir-se por novas aprendizagens. No dia-a-dia os professores experienciam situações quer com as suas crianças quer com os seus pais e/ou outros elementos das comunidades, quer ainda com outros membros do seu contexto de trabalho, situações essas que podem ser potenciadoras de aprendizagem profissional se forem sujeitas a uma reflexão crítica partilhada, quer com os pares, quer com as ciências da educação e com as ciências da especialidade. Passar da repetição mecânica dessas situações ao questionamento das mesmas e à sua reinvenção, resulta numa 'experiência formadora', definida por Josso (2004, p. 48), como "articulação conscientemente elaborada entre atividade, sensibilidade, afetividade e ideação", as quais dotam de sentido as trajetórias profissionais.

Quando os professores falam sobre o que fazem estão a pensar na própria ação, o que pode introduzir novas condições na construção do saber profissional (HOLLY; WALLEY, 1989). A forma crítica como essas reflexões se realizam, a flexibilidade e imaginação aí utilizadas, serão um passo para a aceitação da articulação das práticas com a teoria. Shulman (1991) defende que, para se ser professor, é preciso não só ter algumas skills, mas também fazer constantes reflexões sobre o seu trabalho, entendendo que o saber profissional passa por um processo de autoconstrução, a que se acrescenta, partilhado.

Os conhecimentos e princípios dos professores são planeados no sentido de racionalizar as técnicas da profissão e, como tal, são orientados para determinados fins práticos e sociais úteis. $\mathrm{O}$ cerne para a utilização adequada desses saberes é o diagnóstico sobre as situações, entendido este como um processo cognitivo de análise de acontecimentos e de identificação de vias alternativas de ação, com antecipação das consequências, a longo prazo, das ações e decisões tomadas no momento. Será esse um tipo de saber que parte também da reflexão e da experiência construída nos processos de socialização profissional. Se a longa socialização nos contextos profissionais é uma das componentes formativas mais valorizada, os professores, tendo passado a maior parte do seu tempo de vida na escola -, primeiro como alunos e, de imediato, como docentes -, serão, à partida, os profissionais mais socializados na sua ação. No entanto, ao longo dos anos, a sua posição pessoal dentro dessa estrutura vai-se alterando, passando de aluno a formando e depois a formador, com o que isso significa de complexificação nas interações e na reformulação de perspectivas sobre essa estrutura formal, o que irá repercutir-se na realização do seu trabalho. O conhecimento integrado é, assim, uma das condições para criar novas perspectivas e tornar-se mais relevante para os professores na medida em que os prepara para os seus múltiplos papéis a ativar na sociedade (SARACHO; SPODEK, 1992).

Uma síntese sobre os saberes dos professores leva-nos a dizer que a ação docente, sobretudo nos primeiros níveis educativos, é integradora e direcionada para práticas globais, sujeita a esquemas não padronizados e com uma organização nem sempre muito visível, em que o pensamento pessoal de cada profissional surge como uma marca distintiva. A formação dos professores, nas perspectivas apontadas ao longo do texto, tem que atender aos tipos de saber específicos da profissão, incorporando o conhecimento que se vai produzindo. A ação docente desenvolve-se em contextos culturais, com uma localização espáciotemporal, pelo que a participação de cada profissional no seu processo formativo tem que se concretizar como um princípio e uma prática efetiva.

As professoras que participaram do processo de mobilidade entre Brasil e Portugal escolheram investir no desenvolvimento profissional. Segundo Nóvoa, "estar em formação implica um investimento pessoal, um trabalho livre e criativo sobre os percursos próprios, com vista à construção de uma identidade, que é também uma identidade profissional". (NÓVOA, 1997, p. 25). Como nos relata Teresa, "faltava-me algo para ser excelente profissional, por isso quis Pedagogia". A professora já havia cursado o magistério, que a habilitou para trabalhar com os anos iniciais do ensino fundamental, pois no Brasil da década de 1980 não havia obrigatoriedade de formação no ensino superior para atuar nesse nível de ensino. A escolha pela graduação em Pedagogia parece ter sido motivada pelo comprometimento com a profissão, o que fez com que Teresa se empenhasse em avançar em sua formação. O mesmo aconteceu com Analúcia: 
No que que diz respeito ao meu pós-doc em Portugal, de início para sair liberada na minha escola, não foi fácil, pois apesar de ter feito meu doutorado dando aulas na Educação Infantil, trabalhando, eu sempre gostei de estudar, conhecer e investigar sobre questões ligadas a infância $e$ a formação de professores. Acontece que na ESEBA, a política de qualificação docente, não tinha espaço para uma solicitação de pós-doc. Portanto, quando consegui foi uma grande vitória pessoal e profissional. (ANALÚCIA, 2014)

Nesse percurso de identificação formativa, as professoras dinamizaram a construção de suas identidades profissionais, visto que esta está "associada quer às interacções que $\mathrm{o}$ docente estabelece com a sua profissão, com as comunidades com que trabalha e com o seu grupo de pares, quer com a construção simbólica, pessoal e inter-pessoal que essas interacções implicam." (SARMENTO, T., 2002, p. 115). É possível perceber esse processo de identificação, por exemplo, na Teresa, ao participar de diferentes contextos de atuação profissional e de formação:

E foi também um ano que eu trabalhei na... antigamente era o Jardim Rosinha, depois passou a ser Paulo Freire, foi uma homenagem que na época eu estava como assistente, Paulo Freire, até por ser seguidora dele, naquele tempo.

(...) Ele (Paulo Freire) esteve lá num congresso, foi quando eu o conheci. Tive o prazer porque eu fazia parte da organização e tive o prazer de ouvi-lo a falar pessoalmente. Foi até o sindicato que nos levou Paulo Freire a falar no Teatro Clara Nunes, na Praça da Moça. Ele foi até lá, foi um dos congressos mais gratificantes para ouvir, que nunca mais esqueci a voz dele por sinal, que era uma voz muito calma, muito suave e muito doce, uma pessoa que quem o conheceu não consegue esquecer. E as obras dele são impecáveis, não há quem diga que não seja. E qualquer pessoa que tenha lido um bocado dele acaba por amar a educação. Acho eu, não sei, eu falo por mim. (TERESA, 2014)

As identidades profissionais, por sua vez, não têm um tempo para que fiquem estabelecidas definitivamente, pois, à medida que vão progredindo na carreira e na vida pessoal, "os profissionais reinterpretam e reformulam as perspectivas profissionais que têm a seu próprio respeito, com base na reflexão que fazem sobre os seus percursos e na configuração de sentidos que conferem à realidade." (SARMENTO T., 2002, p. 114)

\section{Algumas reflexões finais}

As conclusões preliminares apontam para um amplo conjunto de indicadores da identidade de ser professor, como, por exemplo, a interação ser a base de toda a ação educativa, a riqueza que o cruzamento de saberes e experiências proporciona, a necessidade de cada um conseguir fazer $o$ cruzamento entre vivências pessoais e profissionais e a pertinência da contextualização educativa.

A principal aprendizagem da Analúcia terá sido o reconhecimento do papel das crianças na ação educativa. A principal aprendizagem da Teresa foi no nível da articulação da escolarização com a vida quotidiana - muito freiriana; a criatividade; o construtivismo; a contextualização; a relativização da riqueza e da pobreza; dialogar com os alunos no pequeno e no grande grupo e o dar a eles aquele trabalho, isso no nível do Pré-Escolar, aqueles momentos em que eles são os que atuam naquele espaço.

Teresa e Analúcia apresentaram em suas narrativas um segmento de suas vidas. Ao rememorar as suas experiências, elas deram "sentido ao mundo vivido e à relação entre esse mundo e à interpretação que fazem dele; entre a experiência humana e o ato de narrar; entre a história individual e a história coletiva". (NACARATO; PASSEGGI, 2012, p. 211). Dessa forma, neste trabalho procuramos evidenciar o quanto a mobilidade de professores entre Brasil e Portugal tem proporcionado o entrelaçamento de culturas, o enriquecimento de experiências e a ampliação e aprofundamento de conhecimentos profissionais.

O professor, ao narrar a sua história, procura dar sentido às suas experiências e, ao longo desse percurso, tem a possibilidade de construir uma nova "interpretação de si: reinventa-se" (PASSEGGI, 2011, p. 147). Assim aconteceu com Teresa e com Analúcia, ao cruzarem o mar em busca de desafios e de desenvolvimento profissional. 


\section{Referências}

ALARCÃO, Isabel. Professor-Investigador. Que sentido? Que formação? In: Campos, B. (Org). Formação Profissional de Professores no Ensino Superior. Porto: Porto Editora, 2001. p. 21-30.

ALONSO, Luísa G. Inovação Curricular, Formação de Professores e melhoria da escola uma abordagem reflexiva e reconstrutiva sobre a prática da inovação/formação. Braga: IEC-UM (policopiado), 1998.

CANÁRIO, R. A prática profissional na formação de professores. In: Campos, B. (Org), Formação Profissional de Professores no Ensino Superior.Porto: PortoEditora, 2001. p. 31-45.

FORMOSINHO, J.Universitisation of teacher education.GassnerOtmar (Ed.) Strategies of change in teacher education: European views.Feldkirch, Austria: ENTEP (European Network on Teacherducation Policies), 2002. p. 105 - 127.

FOUCAULT, M.Ditsetécrits 1984 , Des espaces autres (conferência no Cercle d'étudesarchitecturales, 14 de março 1967), in Architecture, Mouvement, Continuité, $\mathrm{n}^{\circ} 5$, outubro 1984, pp. 46-49.

\section{Desespacesautres,}

Héterotopies.In: Ditsetécrits. France: ÉditionsGallimard, 2002.

HOLLY, Mary; WALLEY, Carl.Teachers as professionals. In: Mary Louise Holly \&Caven S, Mcloughlin (Orgs.). Perspectives on Teacher Professional Development.Londres: The Falmer Press, 1989.

MARCELO, Carlos. Formación del profesorado para el cambio educativo.Barcelona: PPU, 1994.

NACARATO, Adair Mendes e PASSEGGI, Maria da Conceição. Olhar para si e superar marcas deixadas pela matemática escolar: reflexões de uma futura professora sobre seu percurso de formação. In: OLINDA, Ercília M. B. de. (Org). Artes do Sentir: trajetórias de vida e formação. Fortaleza: Edições UFC, 2012. p. 208 - 225.
NÓVOA, Antônio. Formação de professores e profissão docente. NÓVOA, Antônio (Coord.). Os professores e a sua formação. Lisboa: Dom Quixote, 1997.p. $15-33$.

OLIVEIRA-FORMOSINHO, Júlia. O Desenvolvimento Profissional das educadoras de Infância - um estudo de caso.Braga: IEC-UM, 1998. (Tese de Doutoramento)

PASSEGGI, Maria da Conceição. Entre a vida e a educação: pesquisa (auto)biográfica, docência e profissionalização. In:Educação em Revista, 27 (1), 2011. p. 369-386.

A experiência

em formação. Disponível em: http://revistaseletronicas.pucrs.br/ojs/index.php/face d/article/view/8697. Acesso em: 10.set.2013.

PEIXOTO, P. Multiculturalismo, transculturalisnmo e heterogénese urbana: composições da diversidade para a produção do transconhecimento. In Visões, Revista Cientîfica da Faculdade Salesiana $\mathbf{M}^{\mathbf{a}}$ Auxiliadora, $n^{\circ} 7,2009$. p.50-69.

ROLDÃO, $M^{\mathrm{a}}$ Céu. A formação como projecto. Do plano mosaico ao currículo como projecto de formação. in Campos, B. (Org).Formação Profissional de Professores no Ensino Superior. Porto: Porto Editora, 2001. p. 6 -20.

SARMENTO, Teresa. Histórias de vida de educadores de infância. Lisboa: IEE, 2002.

SHULMAN, Lee. Ways of seeing, ways of knowing: ways of teaching, ways of learning about teaching. Journal of Curriculum Studies, 23-5, 1991. p. 393-395.

SPODEK, Bernard; SARACHO, Olivia; PETERS, Donald.Professionalism and the Early Childhood Practitioner.New York: TeachersCollege Press, 1998.

WILLMS, E. e CARVALHO, A. O tema gerador no estágio do curso de pedagogia do ICHS/CUR/UFMT: pressupostos teóricos. In: Rocha, S. (Org) Formação de Professorese práticas em discussão. Cuiabá: EdUFMT, 2008. p.21-37. 


\section{Sobre as autoras:}

Silvia Maria Medeiros Caporale: é Licenciada em Matemática, Mestre e Doutoranda em Educação na Universidade São Francisco, onde também participa do Grupo de Estudos e Pesquisas HIFOPEM - Histórias de formação de professores que ensinam Matemática. Atualmente é Professora do Departamento de Ciências Exatas da Universidade Federal de Lavras.

Teresa Jacinto Sarmento: realizou doutoramento em Estudos da Criança, com uma investigação em identidades profissionais. Atualmente é Professora Auxiliar no Instituto de Educação - Universidade do Minho, onde tem se dedicado à docência e à investigação sobre as problemáticas da formação de professores, da infância, histórias de vida de profissionais da educação, e da relação escola-famílias-comunidades.

Artigo recebido em março de 2015.

Artigo aprovado em maio de 2015. 